\title{
Supporting materials:
}

\section{${ }^{17} O$ ESEEM evidence for exchange of the axial oxo ligand in the molybdenum center of the high $\mathrm{pH}$ form of sulfite oxidase}

Andrei V. Astashkin, Changjian Feng, Arnold M. Raitsimring, John H. Enemark*

Department of Chemistry, University of Arizona, Tucson, AZ 85721-0041.

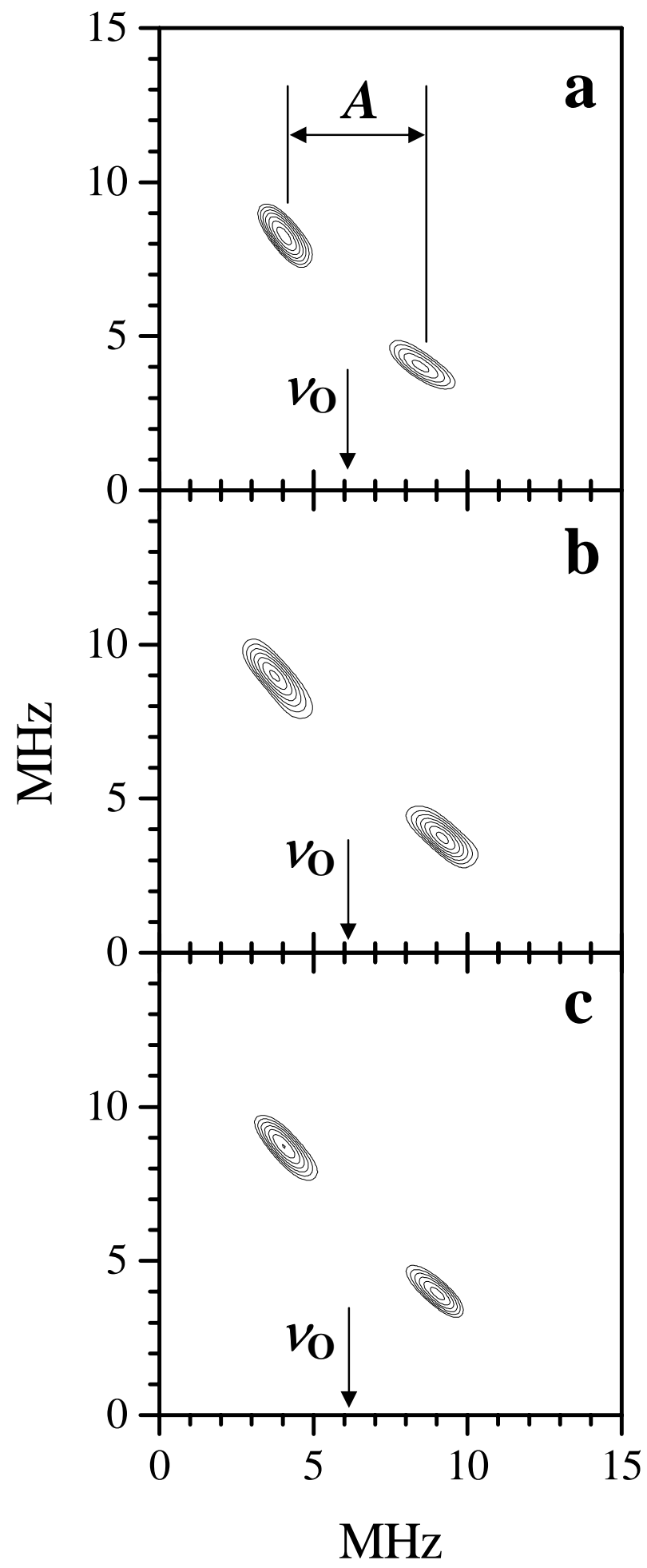

Figure S1. $(++)$ quadrants of the ${ }^{17} \mathrm{O}$ HYSCORE spectra of $h p H$ SO in $\mathrm{H}_{2}{ }^{17} \mathrm{O}$ obtained at turning points of the EPR spectrum. The magnetic fields corresponding to panels (a), (b) and (c) are, respectively, 1052 $\mathrm{mT}\left(g_{\mathrm{Z}}\right), 1063.2 \mathrm{mT}\left(g_{\mathrm{Y}}\right)$ and 1068.4 $\mathrm{mT} \quad\left(g_{\mathrm{X}}\right)$. Other experimental conditions: mw frequency, 29.252 $\mathrm{GHz}$; mw pulses, $4 \times 15 \mathrm{~ns}$; time interval $\tau$ between the first and second mw pulses, 200 ns; measurement temperature, $20 \mathrm{~K}$. The value of the ${ }^{17} \mathrm{O}$ Zeeman frequency, $v_{\mathrm{O}}$, is indicated by an arrow in each panel. Panel (a) also shows how the $h f i$ constant is measured. 
Scheme S1: Proposed process for the exchange of axial (ax) and equatorial (eq) oxygen groups with ${ }^{17} \mathrm{O}$ enriched water in metal (M) compounds with a cis- $\mathrm{MO}(\mathrm{OH})$ structure (adapted from ref 24). The species in the boxes predominate at equilibrium.

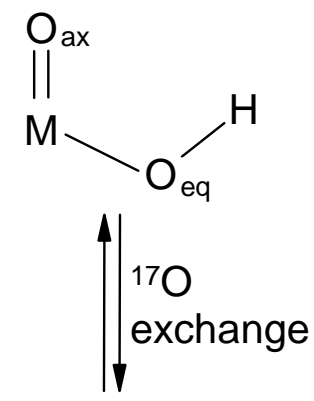

(i)
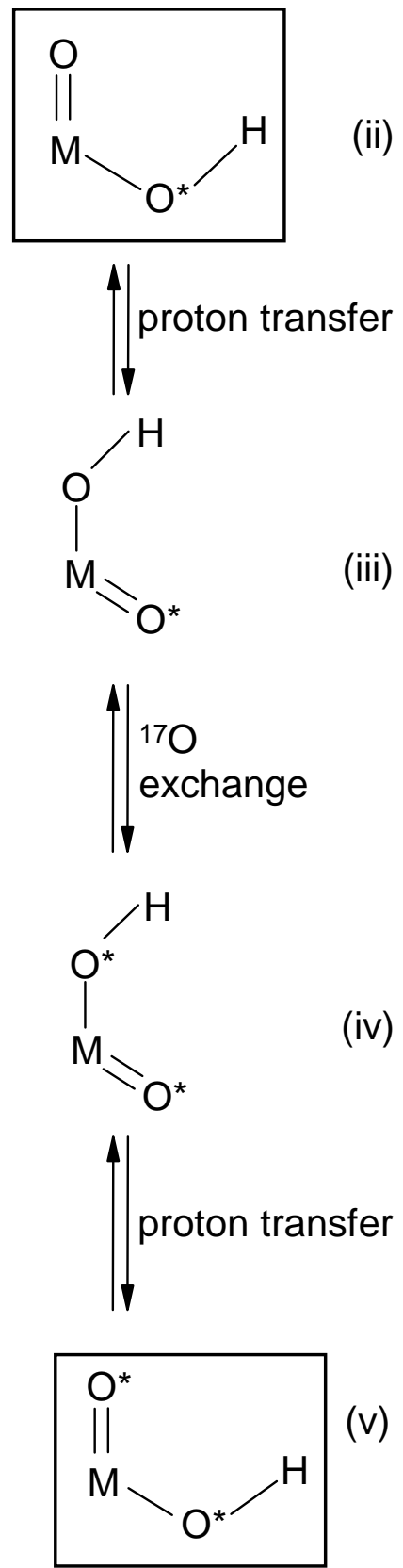